July 2015

\title{
An Ethical Framework for End-of-Life Discussions
}

Mark E. Lones

Advocate Lutheran General Hospital

Follow this and additional works at: http:// digitalcommons.cedarville.edu/

bioethics_in_faith_and_practice

Part of the Bioethics and Medical Ethics Commons

DigitalCommons@Cedarville provides a publication platform for fully open access journals, which means that all articles are available on the Internet to all users immediately upon publication. However, the opinions and sentiments expressed by the authors of articles published in our journals do not necessarily indicate the endorsement or reflect the views of DigitalCommons@Cedarville, the Centennial Library, or Cedarville University and its employees. The authors are solely responsible for the content of their work. Please address questions to dc@cedarville.edu.

\section{Recommended Citation}

Lones, Mark E. (2015) "An Ethical Framework for End-of-Life Discussions," Bioethics in Faith and Practice: Vol. 1 : No. 1 , Article 4. DOI: $10.15385 /$ jbfp.2015.1.1.4

Available at: http://digitalcommons.cedarville.edu/bioethics_in_faith_and_practice/vol1/iss1/4 


\title{
An Ethical Framework for End-of-Life Discussions
}

Browse the contents of this issue of Bioethics in Faith and Practice.

\author{
About the Author(s) \\ Rev. Mark Lones is a chaplain at Advocate Lutheran General Hospital in Park Ridge, IL.
}

\section{Institution/Affiliation}

Advocate Lutheran General Hospital

\begin{abstract}
The primary goal of medical care is to assist patients to address medical issues which may threaten their health in order to preserve and restore the quality of the patients' life. However, when a patient's prognosis for meaningful survival is poor, there is a change in focus from restorative care to palliative care. The transition from "cure to comfort" is one of the most challenging and important medical care decisions the patient and family may encounter. The purpose of this article is to help give patients, families and care-givers an ethical framework to effectively discuss treatment options, values, and preferences during the change from restorative care to palliative care.

Having discussed the many obstacles which impede meaningful participation for end-of-life decision making, the focus of this article then turns to the ethical concerns which should undergird end-of-life decisions. Perhaps the most significant ethical consideration is not patient autonomy but the valuing the personhood of the patient. The main objective of end-of-life discussions should be to prepare patients and their families to work with the medical team to make the best possible "in-the-moment" care decisions. These discussions should focus on outcomes, not treatments. These expected outcomes should respect the personhood of the patient, their values and priorities. Our society has struggled for several decades to define appropriate end-oflife medical care which promotes life and does not simply prolong a person's natural death. This article takes a step toward defining an ethical framework for effective end-of-life discussions.
\end{abstract}

\section{Keywords}

Ethics, end-of-life, personhood, palliative care, values, ethical framework, goals of care

\section{Creative Commons License (c) $(1)(9)$}

This work is licensed under a Creative Commons Attribution-Noncommercial-No Derivative Works 4.0 License. 


\title{
An Ethical Framework for End-of-Life Discussions
}

\author{
Rev. Mark E. Lones, D.Min. \\ Chaplain Resident, Advocate Lutheran General Hospital
}

\section{Introduction:}

The primary goal of medical care is to assist patients to address medical issues which may threaten their health in order to preserve and restore the quality of the patients' life. However, when a patient's prognosis for meaningful survival is poor, there is a change in focus from restorative care to palliative care. Many patients fear that in the last stages of an illness, they may receive more high-tech medical care than they desire. However, once patients experience these final health stages, they are often more willing to accept aggressive treatments with limited benefits. Presently, there is a strong and growing public and professional interest in improving medical end-of-life decision making.

The transition from "cure to comfort" is one of the most challenging and important medical care decisions the patient and family may encounter. Truog underscores two reasons why this transition is so arduous. "First is the widespread and deeply held desire not to be dead. Second is medicine's inability to predict the future, and to give the patients a precise, reliable prognosis about when death will come. If death is the alternative, many patients who have only a small amount of hope will pay a high price to continue the struggle”. ${ }^{i}$ The purpose of this article is to help give patients, families and care-givers an ethical framework to effectively discuss treatment options, values, and preferences during the change from restorative care to palliative care.

Rosenfeld suggests the current practice of end-of-life discussions falls far short of the ethical ideal for numerous reasons. Patients lack sufficient medical knowledge to make informed choices. Family members often do not understand the patient's values and preferences. And, advance directives have been largely ineffective in clinical practice. Rosenfeld concludes, “The disparity between contemporary ethical standards and actual clinical practice may be a marker of poor quality in end-of-life care. Alternatively, it could suggest that ethical standards do not fully capture patients' own goals for decision making during serious illness". ii

\section{Factors that Affect End-of-Life Decision-Making:}

A survey of the literature reveals a dissatisfaction with patient/family involvement with end-of-life treatment decisions. Over the last couple of decades, there has been a paradigm shift in American culture from a paternalistic model of medical practice to an emphasis on patient autonomy. ${ }^{\text {iii }}$ Respect for patient autonomy has become the core principle that influences physicians, patients, and family decision-making roles. Patients who lack capacity may have their choices guided by verbal and written statements (i.e. advance directives) they made prior becoming incapacitated. Patients may also appoint surrogates who are ethically and legally recognized to make assessments on the patient's behalf.

Bioethics in Faith and Practice vol. 1, no. 1, pp. 13-19. ISSN 2374-1597

(C) 2015, Mark Lones, licensed under CC BY-NC-ND (http://creativecommons.org/licenses/by-nc-nd/4.0/ ) 
Patients and families are seeking to be more involved in the decision-making process. However, they often define involvement in different ways, ranging from having knowledge about specific medical procedures to having the decisive say. If the physician merely provides treatment alternatives and asks patients and families to choose among those options it may make the patients and families feel solely responsible for the medical decisions. On the other hand, some patients and families prefer to have physicians make treatment decisions. When communication is directed to the patient separately from the family and with a different level of degree, the family may be uncertain about what the patient knows and to what he has consented. Some seriously ill patients do not wish to discuss with their physicians their preference for specific treatments. If the family is to participate with the patient and physician in the decision-making process, roles should be clearly defined.

There are many other substantial barriers which impede meaningful participation for end-of-life decision making. It is difficult to consider all the implications of "in-the-moment" end of life treatment decisions. Some patients and families do not want to think about dying. Finally, physicians do not have time for lengthy discussion on advance care planning. ${ }^{\text {iv }} \quad$ These barriers may lead families to feel the healthcare team is trying to impose their personal opinions on the family or pressure them to make decisions too quickly.

The extent of dissatisfaction with patient and family involvement in decision making is underscored by care-givers concerns about the appropriateness of care provided at the end of life. Solomon suggests a gap between views of practicing clinicians and the prevailing guidelines. In the results of a study which surveyed physicians and nurses in five hospitals, almost half $(47 \%)$ of all respondents and $70 \%$ of the house offices stated that they had acted against their conscience in providing end-of-life care. Most caregivers were more concerned about the provision of overly burdensome treatment than about under treatment. Many were disturbed by the degree which technological solutions influenced care and by the under treatment of pain. ${ }^{\mathrm{v}}$

These "concerns of conscience" involved three areas. ${ }^{\text {vi }}$ First, care-givers expressed concerns about inappropriate, overly burdensome care. These concerns about inappropriate care centered on three distinctions:

- Distinctions between withholding vs. withdrawing treatment

- Distinctions between actions of killing and allowing to die

- Distinctions between consequences that are intended and those that are merely foreseen (doctrine of double effect)

Secondly, a sizeable proportion of end-of-life care-givers were reluctant to forgo artificial nutrition and hydration believing medically supplied food and water should always be provided. "Although across professions only a minority (12\%) believed that 'disconnecting a feeding tube is killing a patient,' a sizable proportion (42\%) agreed that 'even if life supports such as mechanical ventilation and dialysis are stopped, food and water should always be continued"'. vii Many of these care-givers did not want to abandon highly vulnerable patients and were unaware that dehydration may reduce suffering in the final hours of life. 
Finally, many healthcare givers recognized a need for better pain relief. Most care givers agreed, in principle, that "providing large quantities of narcotic analgesics does not constitute wrongful killing when the purpose is not to shorten patients' lives but to alleviate pain and suffering”. However, most caregivers in a study conducted by Solomon, reported that "the most common form of narcotic abuse in the care of the dying is under treatment of pain". viii Many physicians and nurses believed that "clinicians give inadequate pain medications most often out of fear of hastening a patient's death. ${ }^{\text {ix }}$

If care-givers have concerns about the appropriateness of care provided at the end of life, this creates an environment where it is difficult to have effective discussions concerning end-of-life decisions. Solomon recommends that attention must be given to the psychology as well as the ethics of moral decision making at the end-of-life. ${ }^{\mathrm{x}}$ Nurses are often the implementers of decisions in which they have not participated and with which they may not agree. Yet these nurses could probably play a greater role in helping patients and families understand the choices they face.

\section{Ethical Concerns to Consider when Discussing End-of-Life Decisions:}

\section{Personhood}

Having discussed the many obstacles which impede meaningful participation for end-of-life decision making, the focus of this article turns to the ethical concerns which should undergird end-of-life decisions. Perhaps the most significant ethical consideration is not patient autonomy but the valuing the personhood of the patient. In this postmodern world where moral confusion has impacted every aspect of culture, clarity regarding the meaning of a person is crucial. The Christian perspective defines human beings as having inherent value. All human beings are a distinct substance that exists ontologically prior to any of its parts. A human being is intrinsically valuable because he is a particular type of substance: a person who is a rational moral agent. The substance view states a person remains identical to himself as long as he exists, even if that person is not presently exhibiting the functions or actions that we typically attribute to active and mature rational moral agents.

In a 2005 national study almost all the respondents valued attributes associated with "being treated as a whole person"xi. In end-of-life discussions, the family needs the opportunity to express to the healthcare team the value of their loved one. They want their family member to be seen as a whole person: who he was; his strengths, his role in the family and what gave his life meaning and purpose. Thus it is essential to have a broad, holistic view of the patient's entire life.

To be treated as a whole person means that end-of-life discussions should center on high quality interpersonal care that affirms the patient's personhood, resulting in the preservation of self. These decisions are founded in four principles:

1. Value people as persons

2. Treat people as individuals

3. Look at the world from their perspective

4. Provide a positive social environment 


\section{Communication}

If the family is to participate with the patient and physician in the decision-making process, roles and expectations should be clearly defined. The decision-making authority in end-of-life treatment decision should be based on each respective area of expertise. Physicians should be given authority based on their technical expertise in prognostication and treatment, and patients/families based on their primary concern for the patient's well-being, values and priorities. The physician and family members would then collaborate, blending the expertise of all those involved. Rosenfeld writes: "Informants felt that the physician's skill in treating serious illness and prognosticating outcomes is critical to his or her decisionmaking authority. However, when functional recovery is not possible, the family's decision-making authority assumes precedence, aided by the doctor's support and technical guidance". xii

Many of the efforts to improve end-of-life decision-making have focused on promoting patient autonomy (i.e. advance directives) to control treatment decisions. In recent years, patients, bioethicists, and clinicians have questioned using autonomy (advance directives) as the central decision-making priority. xiii Advance directives should be viewed as a tool in preparing patients and health care power of attorney agents (HCPOA) for end-of-life decision making. Advance directives are simply one part of the decisionmaking process because it can be difficult for patients and HCPOAs to consider all the implications of “in-the-moment” treatment decisions.

Sudore suggests three key steps to address patients' and HCPOAs' needs for preparation for in-themoment decisions making: “(1) choosing an appropriate surrogate decision maker, (2) clarifying and articulating patients' values over time, and (3) establishing leeway in surrogate decision making”. xiv The main objective of advance care planning is not advance treatment decisions. The goal of advance care planning should be to prepare patients and families to work with their physician to make the best possible "in-the-moment" medical decisions focusing on outcomes, not treatments, which respects the personhood of the patient, their values and priorities.

\section{End-of-Life Medical Care}

Finally, end-of-life discussions should include concerns about the appropriateness of care provided at the end of life. These "concerns of conscience" are threefold: (1) Inappropriate, overly burdensome care. (2) Reluctance to forgo artificial nutrition and hydration believing medically supplied food and water should always be provided. (3) The need for better pain relief.

These family concerns about inappropriate end-of-care center on three ethical distinctions. The first distinction is between withholding verses withdrawing treatment. Most care-givers are psychologically more comfortable withholding treatments than withdrawing them. This may be related to the fact that withholding is passive, while withdrawing is active and associated with a greater sense of moral responsibility. Discussions should focus on an assessment of the relative benefits and burdens to the patient, not the timing of the decision. Treatments should be instituted with a plan for stopping the "trial of treatment" with specific points to evaluate and revise the care plan. Psychologically, families need to be encouraged that they are not abandoning their "loved one”. Rather, the type of care is changing to one of comfort. 
Closely related to the first distinction, the second distinction is between actions of killing and allowing to die. For example, some believe that withdrawal of mechanical ventilation from a patient is unethical, because it would kill the patient. They would argue that since killing is defined as an act that is the proximate cause of a death, then withdrawal of life support is indeed an act of killing. However, legally, the withdrawal of life-sustaining treatments is not considered a killing, and the actions in this regard are simply "allowing the patient to die" from the underlying illness. ${ }^{\mathrm{xv}}$ In these end-of-life discussions, it is important that the family understand the distinction between the withdrawal of life-sustaining interventions and the withdrawal of care. While the withdrawal of interventions is common, the withdrawal of care should never occur.

Helpful in making termination-of-life decisions is the distinction between consequences that are intended and those that are merely foreseen (doctrine of double effect). In other words, there is a difference between giving medications with the intention to kill the patient as opposed to giving medications with the intention to make the patient comfortable, but with the foreseen consequence of potentially hastening the patient's death. The law defines the line between euthanasia and acceptable palliative care. Former U.S. Supreme Court Chief Just Rehnquist writes: "It is widely recognized that the provision of pain medication is ethically and professionally acceptable even when the treatment may hasten the patient's death if the medication is intended to alleviate pain and severe discomfort, not to cause death”. xvi

\section{Conclusion}

The main objective of end-of-life discussions should be to prepare patients and their families to work with the medical team to make the best possible "in-the-moment" care decisions. These discussions should focus on outcomes, not treatments. These expected outcomes should respect the personhood of the patient, their values and priorities. "What would you like your physician to know about you as a person to give you the best care possible?" would be good starting point for these discussions. Questions like, "If you were in this situation, what would you hope for? Or "What worries you the most? should be discussed. Other questions may include: "What if your health changes and your doctors recommend against further treatment?" and "What if it would be too difficult for loved ones to provide care for you to die at home?"

The transition from "cure to comfort" is one of the most difficult and important medical care decisions the patient and family have to encounter. Our society has struggled for several decades to define appropriate end-of-life medical care which promotes life and does not simply prolong a person's natural death. All parties should focus on clarifying the goals of care. Patients and their families should determine what they hope to achieve - restoring health, extending life, or relieving pain and suffering. Physician should provide information about the patient's prognosis and what outcomes can be accomplished by the use of specific interventions. However, physicians should not offer treatments that cannot achieve the goals of care defined by the patient and family. We still have far to go but perhaps this article has offered an ethical foundation to provide a framework for these discussions.

\footnotetext{
' Robert D. Truog, MD, MA, Margaret L Campbell, PhD, RN, FAAN, J Randall Curtis, MD, MPH, Curtis E Haas.
} PharmD, FCCP, John M. Luce, MD, Gordon D. Rubenfeld, MD, MSc, Cynda Hylton Rushton, PhD, RN, FAAN, 
David C. Kaufman, MD. "Recommendations for End-of-life Care in the Intensive Care Unit: A Consensus Statement by the American College of Critical Care Medicine”. Critical Care Medicine 36.3 (2008). 953. doi: 10.1097/CCM.0B013E3181659096

ii Kenneth E. Rosenfeld, Neil S. Wenger, \& Marjorie Kagawa-Singer. End-of-life Decision Making: A Qualitative Study of Elderly Individuals. Journal of General Internal Medicine 15.9 (2000). 620. doi: 10.1046/j.1525-1497.2000.06289.x

iii Rosemary C. MacDonald, Lori E. Weeks, \& Gloria McInnis-Perry.) End-of-life Healthcare Decision-Making: The Intermediary Role of the Ethicist in Supporting Family Caregivers and Health Professionals. Work 40 (2011). 63. doi 10.3233/WOR-2011-1207

iv Rebecca L. Sudore, MD, \& Terri R. Fried, MD. Redefining the “Planning” in Advance Care Planning: Preparing for End-of-life Decision Making. Annals of Internal Medicine 153.4 (2010). 256.

doi:10.7326/0003-4819-153-4-201008170-00008

${ }^{v}$ M. Z. Solomon, L. O'Donnell, B. Jennings, V. Guilfoy, S. M. Wolf, K. Nolan, R. Jackson, D. Koch-Weser, \& S. Donnelley. Decisions Near the End of Life: Professional Views on Life-sustaining Treatments. American Journal of Public Health, 83.1. (1993). 16.

doi: 10.2105/AJPH.83.1.14

vi Ibid., 16.

vii Ibid., 20.

viii Ibid., 19.

ix Ibid., 19.

x Ibid., 21.

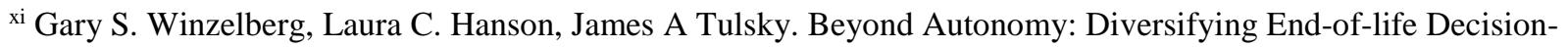
making Approaches to Serve Patients and Families. Journal of the American Geriatrics Society. 53.6. (2005) 1047. doi: $0.1111 / \mathrm{j} .1532-5415.2005 .53317 . \mathrm{x}$

xii Rosenfeld. End-of-life Decision Making: A Qualitative Study of Elderly Individuals. 623.

xiii Winzelberg. Beyond Autonomy: Diversifying End-of-life Decision-making Approaches to Serve Patients and Families. 1047.

xiv Sudore. Redefining the "Planning” in Advance Care Planning: Preparing for End-of-life Decision Making. 258.

${ }^{x v}$ Truog. "Recommendations for End-of-life Care in the Intensive Care Unit: A Consensus Statement by the American College of Critical Care Medicine”. 957.

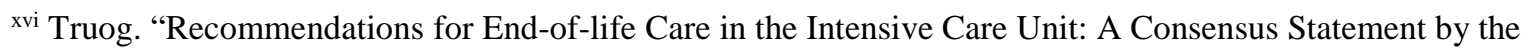
American College of Critical Care Medicine”. 956. 


\section{Bibliography}

Gillam L; Sullivan J. (2011). Ethics at the End of Life: Who Should Make Decisions about Treatment Limitation for Young Children with Life-threatening or Life-limiting conditions? Journal of Paediatrics \& Child Health. 47 (9) 594-598. doi: http://dx.doi.org/10.1111/j.14401754.2011.02177.x

Lind, Ranveig, Nortvedt, Per, Lorem, Geir, Hevrøy, Olav (2013). Family Involvement in the End-of-life Decisions of Competent Intensive Care Patients. Nursing Ethics. 20 (1) 61-71. doi: http://dx.doi.org/10.1177/0969733012448969

MacDonald, Rosemary C., Weeks, Lori E.,\& McInnis-Perry, Gloria (2011) End-of-life Healthcare Decision-making: The Intermediary Role of the Ethicist in Supporting Family Caregivers and Health Professionals. Work 40(63-73). doi http://dx.doi.org10.3233/WOR-2011-1207

Manalo, Maria Fidelis C. MD, MSc (2013). End-of-life Decisions about Withholding or Withdrawing Therapy: Medical, Ethical, and Religio-cultural Considerations. Palliative Care: Research and Treatment 7(1) 1-5. doi: http://dx.doi.org/10.4137/PCRT.S10796

Rosenfeld, Kenneth E., Wenger, Neil S., \& Kagawa-Singer, Marjorie (2000). End-of-life Decision Making: A Qualitative Study of Elderly Individuals. Journal of General Internal Medicine, 15(9) 620-625. doi: http://dx.doi.org/10.1046/j.1525-1497.2000.06289.x

Solomon, M. Z., O'Donnell, L., Jennings, B., Guilfoy, V., Wolf, S. M. Nolan, K., Jackson, R., KochWeser, D., \& Donnelley, S. (1993). Decisions Near the End of Life: Professional Views on LifeSustaining Treatments. American Journal of Public Health, 83(1)14-23. doi: http://dx.doi.org/10.2105/AJPH.83.1.14

Stadnyk, Robin, MacDonald, Rosemary, Weeks, Lori, McInnis-Perry, Gloria (2011). End-of-life Healthcare Decision-making: The Intermediary Role of the Ethicist in Supporting Family Caregivers and Health Professionals. Work. 40(1) 63-73. doi: http://dx.doi.org/10.3233/WOR$\underline{2011-1207}$

Sudore, Rebecca L., MD, \& Fried, Terri R., MD (2010). Redefining the "Planning” in Advance Care Planning: Preparing for End-of-life Decision Making. Annals of Internal Medicine 153 (4)256261. doi: http://dx.doi.org/10.7326/0003-4819-153-4-201008170-00008

Tejwani, Vickram, YiFan Wu, Serrano, Sabrina, Segura, Luis, Bannon, Michael (2013). Issues Surrounding End-of-life Decision-making. Patient Preference \& Adherence. 7(1) 771-775. doi: http://dx.doi.org/10.2147/PPA.S48135

Truog, Robert D. MD, MA, Campbell, Margaret L. PhD, RN, FAAN, Curtis, J Randall MD, MPH, Haas, Curtis E. PharmD, FCCP, Luce, John M. MD, Rubenfeld, Gordon D. MD, MSc, Rushton, CyndaHylton PhD, RN, FAAN, Kaufman, David C. MD (2008). Recommendations for End-oflife Care in the Intensive Care Unit: A Consensus Statement by the American College of Critical Care Medicine. Critical Care Medicine, 36(3) 953-963. doi: http://dx.doi.org/10.1097/CCM.0B013E3181659096 
Winzelberg, Gary S., Hanson, Laura C., Tulsky, James A. (2005). Beyond Autonomy: Diversifying Endof-life Decision-making Approaches to Serve Patients and Families. Journal of the American Geriatrics Society. 53(6) 1046-1050. doi: http://dx.doi.org/10.1111/j.1532-5415.2005.53317.x 